\title{
Cancer Education in Surgery
}

\section{Radoslaw Tarkowski ${ }^{1}$}

Published online: 5 September 2019

(C) American Association for Cancer Education 2019

While cancer remains one of the leading causes of death, several effective tools have shown proven value in reducing mortality rates. Surgery is the oldest, being most effective as part of combined-modality treatment. Surgical curricula traditionally favor the acquisition of technical skills; for many of us surgeons, operating remains a culmination and the most important part of treatment. However, it is not the blade alone that makes the therapy effective. It is not even the dexterity and fighting spirit of the surgeon and the patient, although both play important roles. A fool with a tool is still a fool because surgical treatment of people touched by cancer goes far beyond excision and anastomosis or even reconstruction very near to the original or desired shape.

The etymology of the word surgery comes from the old French surgerie- derived from the Latin chirurgia and originally the Greek kheirourgia (kheir-hand, ergon —work) - in fact, everything in surgery starts with words and not spontaneous, automatic manual action. And, according to Paul Kalanithi, when there is no place for the scalpel, words are the surgeon's only tool [1]. Proper patient information and cancer education are cornerstones of any forthcoming operation, and it is often the surgeon who delivers information about the diagnosis and possible treatment. However, there has historically been no formal training in delivering bad news. At a 1998 meeting of the American Society of Clinical Oncology (ASCO), only $5 \%$ of 400 oncologists reported receiving such training [2]. This important skill has since been successfully incorporated into surgical training, although still missing from the curricula at some universities in both undergraduate and postgraduate programs. Training of nontechnical skills has been included in surgical curricula in the USA by both the American College of

Radoslaw Tarkowski

rt@rakpiersi.net

1 Department of Surgical Oncology, Regional Specialist Hospital, ul. Iwaszkiewicza 5, 55-220 Legnica, Poland
Surgeons and the Association of Program Directors in Surgery Surgical Skills Curriculum.

Skills such as communication with patients and colleagues, cooperation within multidisciplinary teams, leadership, situational awareness, disclosure of medical errors, and coping with stress are mandatory to optimize outcomes of treatment, having the same impact as surgical technique. More Scottish surgeons reported these skills as being mandatory for successful outcomes in surgery (41\%) compared with clinical (31\%) or technical $(27 \%)$ aspects [3]. No surgeon is an island. We work in collaboration with medical and radiation oncologists and have strong support from other health professionals. Communicating with colleagues is therefore very important. Although individuals choosing medicine as a way of life should show high levels of empathy, problems in communication are still present and frequently cause medical errors (43\%, according to Gawandee [4]).

Survival in persons with cancer continues to improve through advances such as earlier tumor detection (due to screening programs and vigilance of the population as an effect of cancer education), more effective systemic treatment, technological innovations, and ultra-specialization of units dedicated to patients with tumors (i.e., breast, colorectal, genitourinary, skin, and soft tissue neoplasms). In one study, the risk of local recurrence of breast cancer decreased from 1.42 per 100 person-years in the interval $1997-2002$ to 0.85 in 2003-2005, and to 0.48 in 2006-2010; the corresponding risks of mortality in these intervals were $1.59,1.22$, and 0.64 , respectively [5]. With more lives saved, however, more cancer survivors are being exposed to side effects of therapy, including mutilating surgery, neuropathy after chemotherapy, postradiation skin changes, or even secondary tumors. Combined treatment influences quality of life mainly during the first year after therapy [6], and the incidence of depression decreases from $50 \%$ in the first year to $25 \%$ in the second through fourth years [7]. When stress levels decrease and patients' attention becomes focused more on quality of life than on aspects of lifesaving, aggressive treatment, side effects become even more recognizable and even cosmetic details can 
be annoying. In April's $J C E$ editorial, Dr. Szumacher points out the important role of patients in providing their feedback and participating in development of curricula [8].

Cancer education enables reductions in tumor incidence and mortality through primary and secondary prevention programs. I was very inspired during the last Annual Meeting of the European Association for Cancer Education (EACE) in Porto, listening to surgeon Dr. Charles Moore talking about the Moving Evidence into Action: Creation of a Tobacco Cessation Program in a Safety Net Healthcare System [9]. Please note the very surgical and dynamic first part of the title.

As a surgical oncologist myself, I have been very happy to deliver cancer education concerning prevention and healthy lifestyles in primary and secondary schools. I appreciated discussing attitudes toward the human papilloma virus (HPV) vaccination program, quite new in Poland some years ago, with parents of the adolescents invited to take part. A reported $15 \%-34 \%$ of the parents had refused to vaccinate their children (unpublished data from the Department of Health Education and Health Promotion, State Sanitary Inspectorate unit in Wroclaw, Poland), so there was a strong need to convince them, especially given the growing activity of the antivaccination movements. Low attendance in recommended screening examinations (cervical cytology, mammography, and colonoscopy) is also an important issue in our population that leads to higher cancer mortality. Observing as a surgeon the correlation between lower stages of disease and less aggressive surgery and adjuvant treatment, I was always happy to encourage adults to take part in screening and share the message with others. I appreciate this part of our activities, maybe a bit far from the operating room but that shares the same goal of reducing cancer burden.

Of course this is a very different situation from that when the words "we shall fight on the beaches, we shall fight on the landing grounds, we shall fight in the fields and in the streets" were said [10], but we should remain active in all possible ways, given that 9.6 million people died from cancer in 2018 alone [11].

A cancer research training program was held in 2017 in my hometown, at Wroclaw Medical University, thanks to the kind support and generous help of Professor Arthur M. Michalek, with support from the Fulbright Commission [12]. Its motto was the words of the Dalai Lama: "Share your knowledge. It is a way to achieve immortality." One could paraphrase:
"Deliver cancer education; it's the way to reduce mortality." A quotation from the Talmud is written on the wall of the operating room of Ichilov Hospital in Tel Aviv, Israel, the theater of beautiful operations: "Anyone who saves a life is as if he saved an entire world."

\section{References}

1. Kalanithi P (2016) When breath becomes air. Random House, New York

2. Baile WF, Buckman R (2005) Breaking bad news: the SPIKES strategy. Comm Oncol 2:138-142

3. Baldwin PJ, Paisley AM, Paterson-Brown S (1999) Consultant surgeons' opinions of the skills required of basic surgical techniques. Br J Surg 86:1078-1082

4. Gawandee AA, Zinner MJ, Studdert DM et al (2003) Analysis of errors reported by surgeons at three teaching hospitals. Surgery 133: 614-621

5. Botteri E, Veronesi P, Vila J, Rotmensz N, Galimberti V, Thomazini MV, Viale G, Orecchia R, Goldhirsch A, Gentilini O (2017) Improved prognosis of young patients with breast cancer undergoing breast-conserving surgery. Br J Surg 104:1802-1810

6. Schover LR, Yetman RJ, Tuason LJ, Meisler E, Esselstyn CB, Hermann RE, Grundfest-Broniatowski S, Dowden RV (1995) Partial mastectomy and breast reconstruction. A comparison of their effects on psychosocial adjustment, body image, and sexuality. Cancer 75:54-64

7. Burgess C, Cornelius V, Love S, Graham J, Richards M, Ramirez A (2005) Depression and anxiety in women with early breast cancer: five-year observational cohort study. BMJ 330:702

8. Szumacher E (2019) Patients' engagement in medical education. J Cancer Educ 34:203-204

9. Moore CE. Moving evidence into action: creation of a tobacco cessation program in a safety net healthcare system. Presented at the 32nd Annual Scientific Meeting of the European Association for Cancer Education, Porto, Portugal, May 7-11, 2019. https:// www.eaceporto2019.org/media/filer_public/18/59/1859073a4291-46f0-80ba-bbbe5fc1f08c/link moore eace2019.pdf

10. Churchill W. Speech to the House of Commons, Parliament of the United Kingdom. June 4, 1940

11. International Agency for Research on Cancer, World Health Organization. Latest global cancer data: Cancer burden rises to 18.1 million new cases and 9.6 million cancer deaths in 2018 . Press release no. 263, September 12, 2018. http://www.who.int/ cancer/PRGlobocanFinal.pdf

12. Michalek A, Tarkowski R (2017) Fulbright specialist in Poland. J Cancer Educ 32:247-251

Publisher's Note Springer Nature remains neutral with regard to jurisdictional claims in published maps and institutional affiliations. 